\title{
Influences of Organizational Culture in the Adoption of Agile Methodologies in Information Systems Development
}

\author{
A Systematic Mapping

Gerson Correia da Silva
Junior
Universidade Federal de
Goiás (UFG)
Goiânia, Brazil \\ gersoncorreia@outlook.com \\ João Paulo Amaral \\ Universidade Federal de \\ Goiás (UFG) \\ Goiânia, Brazil \\ joaopaulosi1@hotmail.com \\ Patrícia Gomes \\ Fernandes Matsubara \\ Universidade Federal do Mato \\ Grosso do Sul (UFMS) \\ Campo Grande, Brazil \\ patricia@facom.ufms.br \\ Valdemar Vicente \\ Graciano Neto \\ Universidade Federal de Goiás (UFG) \\ Goiânia, Brazil \\ Universidade de São Paulo (USP) \\ São Carlos, Brazil \\ valdemarneto@inf.ufg.br
}

\begin{abstract}
Information Systems (IS) industry has been pressured to deliver software products under reduced time-to-market and restrict budget. Agile Methodologies (AM) have been adopted to meet those aforementioned needs by the adoption of self-managing teams, iterative development cycles, fast delivery, and focus on functional software. Adoption of AM requires a suitable organizational environment, with significant changes in the employees' behavior and in the working processes, impacting, and suffering the impact of Organizational Culture (OC). In this direction, methods, actions, and policies must be thought to align the company's OC to the use of AM, in such a way that both can benefit each other. However, there is a lack of proposals that systematically investigate how to align both $\mathrm{OC}$ and $\mathrm{AM}$. In this sense, a systematic mapping study (SMS) was conducted to identify studies that associate OC in initiatives of AM adoption. This paper presents the state-of-the-art about the influence of $\mathrm{OC}$ in the adoption of AM. The main contribution of this paper is bringing up an overview of the area, indicating perspectives of research, and exposing (i) a list of actions which have been reported to align OC and AM; (ii) OC factors recognized as essential to the successful adoption of AM; and (iii) the perceptions on a lack of awareness about the influence of OC in IT organizations.
\end{abstract}

Permission to make digital or hard copies of all or part of this work for personal or classroom use is granted without fee provided that copies are not made or distributed for profit or commercial advantage and that copies bear this notice and the full citation on the first page. To copy otherwise, to republish, to post on servers or to redistribute to lists, requires prior specific permission and/or a fee.

SBSI 2015, May 26th-29th, 2015, Goiânia, Goiás, Brazil

Copyright SBC 2015.

\section{Categories and Subject Descriptors}

H.0 [Information Systems]: General; K.4.3 [Organizational Impacts]: Management of Computing and Information Systems-Project and People Management, Systems development

\section{General Terms}

Information Systems, Systematic Mapping

\section{Keywords}

Organizational Culture, Agile Methodologies, Sociotechnical approach

\section{INTRODUCTION}

Information Systems (IS) software development is a complex activity. It inherently requires a sociotechnical approach. On one hand, social dimension comprises people involved in a project, the current culture in the organization, interactions among stakeholders, communication, and the entire spectrum of human aspects; while technical dimension includes a collection of processes, methods, techniques, and tools used to design the IS product.

Organizational Culture (OC) is a noteworthy social dimension. It corresponds to the set of assumptions and beliefs shared by a group [28]. It influences the the work in the organization, impacting the routine, productivity, and delivery of results [23]. OC impacts employees routine, hierarchy, communication, teamwork, and it emerges when a set of assumptions are established by a group, becoming consolidated and recurrent in the daily work as the "correct form" of conducting the work.

On the other hand, time and budget pressures on Information Technology (IT) organizations have required the use of software development approaches which fastly deliver software [4]. In this context, Agile Methodologies (AM) have been adopted [2] for bringing a lighter approach to the 
software development process, giving priority to social interaction, collaboration, and reduced documentation, meeting budget restrictions, time, and quality [1].

AM impose changes in the way people conduct their work. $\mathrm{AM}$ and $\mathrm{OC}$ are related and compose a bidirectional relationship where the cultural context can enhance some aspects of AM. On the other hand, AM can modify the cultural context in which it was inserted $[18,35]$. Considering this mutual influence, it is necessary to propose approaches that align both perspectives of IS development, making OC and AM harmonically coexist in the organization. In this direction, a growing interest in the investigation of these areas has been perceived $[5,7,14,29]$. Recently studies have been conducted to investigate how OC influences the adoption of $\mathrm{AM}$, and how, conversely, these methods influence the culture $[18,22,32,35]$.

This paper presents results of a Systematic Mapping Study (SMS) that has been carried out to elucidate how OC and the adoption of AM influences each other in IS software development companies. For this, Section 2 presents some background; Section 3 briefly describes details on the methodology that guides the work, and reports the results; Section 4 brings some discussion; and finally, Section 5 presents conclusions and points out future work.

\section{BACKGROUND}

Agile Methodologies (AM) are distinguished from traditional software development methods by providing productivity, with focus on social interactions, adaptation to change, and constant delivery [9]. They provide strategies to organize teams and to prepare them for changes, enhancing communication with stakeholders [1], meeting quality and agility. In recent years, an increasing adoption of AM in the development of IS has happened due to the benefits it promises [2]. However, there is a low consensus of what can be considered agile and what is, in fact, agile. This concept depends on the context, and varies according to the perceptions of each group [26]. Indeed, the use of AM principles do not necessarily guarantee that the development will really exhibit such agility, since results are influenced by the way the team works. Thus, the use of AM can promote agility for some organizations, and not in others [18]. In this context, the concept of "emerging agility" [18] is considered an emergent property that may arise or not from the use of AM. It depends on the practices adopted in the organization. For the scope of this paper, the definition of 'agility' considered will be that one proposed by the Agile Manifesto [1], (i) focusing people and interactions over processes and tools; (ii) enhancing responsiveness to changes over following a plan; and (iii) enhancing collaboration with the client rather than the negotiation of contracts.

On the other hand, Organizational Culture (OC) is a major factor that also influences IS software development. OC is a framework of assumptions of a group, learned while solving problems along the years. This set of principles was enough well-succeeded to be considered valid, and to be taught to new members as the correct way of perceiving, thinking, and feeling in the organization [27]. OC is intrinsic to the relations within the company [16], influencing interpersonal relationships. It is usually stable and hard to change [27]. This can generate resistance when changes in internal processes are required [27].

Schein (1999) reports OC as a three-level stack. Figure
1 shows those levels: artifacts level, values level, and assumptions level [27]. The first level is the most exposed and easier to be identified. It consists of features that are visible/tangible, such as the arrangement of employees' tables in the work space, their clothing, routines, and hierarchy. The second level is values. They materialize the way of acting shared by members of a group, such as ethics, working philosophies, rules of behavior, strategies, and objectives. Finally, the third level classifies individual and collective assumptions internalized by members of an organization, such as perceptions and feelings. The fundamental difference between second and third levels is related to perception: second level is more evident (as a behavior rule), while the third level is not usually evident, but influences on shared values (such as an apprehension feeling due to the pressure for results).

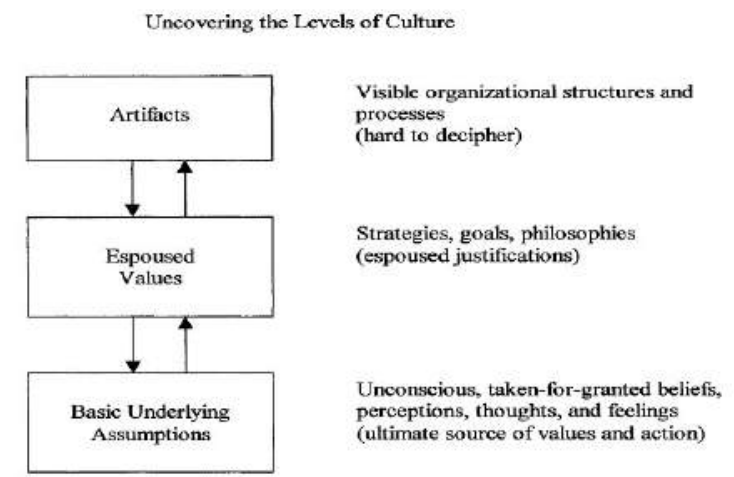

Figure 1: Levels of OC seconds Schein [28].

$\mathrm{OC}$ and $\mathrm{AM}$ can be considered quite orthogonal. However, they are related, and this relationship has an impact on the success of the adoption of AM in an organization [6]. Communication, for example, is an inherent OC factor, and a factor encouraged as practice in AM guides. Companies which adopt AM need to be flexible to changes, and flexibility is an OC factor. Then, there is a need for harmony between the methodology and the culture established in the organization. Thus, a convergence among OC and AM is relevant to study.

\section{SYSTEMATIC MAPPING}

A Systematic Mapping Study (SMS) was conducted to investigate the association between $\mathrm{OC}$ and AM. SMS is a literature review procedure to examine primary studies of a research area. From this analysis, data are collected to answer research questions [31]. SMS is guided by a protocol which specifies research questions, and inclusion and exclusion criteria followed to select studies and to validate the findings [20]. SMS brings many benefits, such as identifying future perspectives of research, as well as offering an extensive analysis of a research area. SMS is different from the systematic literature review (SLR) because SLR delivers its results on the analysis of very specific research questions. SMS, on the other hand, covers a research point under a broader perspective [21].

SMS was conducted to identify primary studies related to OC within the context of AM adoption. It was conducted from October 2014 to December 2014, and involved four researchers, one with expertise in OC, and all with relevant 
knowledge in AM. We used principles proposed by Kitchenham and Peterson et al. [19] as reference to conduct this mapping. Briefly, the process was conducted following three phases: (i) planning, (ii) conduction, and (iii) reporting $[8,13]$.

\subsection{Phase 1: Planning}

During the planning phase, the protocol was defined. It guides the conduction of the SMS, and consists of the research questions, search strategy, selection criteria of primary studies, data extraction, and methods for results synthesis.

1) Research Questions To investigate how OC and AM influence each other, the following research questions (RQ) have been proposed:

RQ 1: Which set/collection of methods, techniques, actions, processes and/or activities have been used to align OC and $\mathrm{AM}$ adoption?

RQ 2: Which OC factors impact the success of the AM?

RQ 3: Organizations implementing AM have awareness about the influence of $\mathrm{OC}$ in their projects?

RQ 4: Which difficulties are reported by studies investigating $\mathrm{OC}$ in the context of AM?

2) Strategy Research The search string was prepared including the most common terms related to OC and AM, and their synonyms. The final search string is shown in Table 3.1. The following scientific bases were chosen to find the primary studies: ACM Digital Library ${ }^{1}$, IEEEXplore ${ }^{2}$, Science Direct ${ }^{3}$, Scopus $^{4}$, and Web of Science ${ }^{5}$. Those bases were chosen due to the greater coverage and accuracy of results they offer, comprising a large number of conferences and specialized journals in IS area [11].

(agile AND (method OR methods OR methodology OR
methodologies OR approach OR approaches OR practice
OR practices OR principle OR principles OR process OR
processes OR technique OR techniques) AND (culture
OR cultural) AND (organizational OR organization OR
organizations OR organisation OR organisations))

Table 1: Search String

3) Inclusion and Exclusion Criteria In order to select which studies are suitable for the scope of this mapping, the following inclusion criteria were determined:

IC 1: The study investigates the $\mathrm{OC}$ in the context of $\mathrm{AM}$;

IC 2: The primary study presents detailed and well defined OC models;

IC 3: The study is based on previous works, which also addresses the $\mathrm{OC}$ in the AM context;

IC 4: Study presents research with results, validation, and justifications which reports the importance of OC regarding AM.

Exclusion criteria (EC) were prepared to eliminate studies that do not present contribution to answer the research questions. EC are presented below:

EC 1: Primary study does not even mention AM;

EC 2: Primary study does not even mention OC;

\footnotetext{
${ }^{1}$ http://dl.acm.org/

${ }^{2}$ http://ieeexplore.ieee.org/Xplore/home.jsp

${ }^{3} \mathrm{http}: / /$ www.sciencedirect.com/

${ }^{4}$ http://www.scopus.com/

${ }^{5}$ https://webofknowledge.com/
}

EC 3: Primary study was not written in english or portuguese;

EC 4: Primary study does not have full content, or it does not have an abstract;

EC 5: The primary study is directly related to another primary study of the same author. In this case, only the most recent primary study will be considered;

EC 6: The primary study consists of a collection of papers, for example, a conference or workshop;

EC 7: The primary study is not only available on a freeaccess base available in the place where the research was conducted.

4) Quality Questions In order to assess the quality of the selected studies according to the criteria previously established, the following quality questions (QQ) have been prepared based on a list of QQ commonly used in similar evidence-based studies $[3,12]$ :

QQ 1: There is a consistent reason for why the study has been conducted;

QQ 2: The authors present an overview of the related work and the area of the context in which the study is developed; QQ 3: There is an adequate description of the context (industry, research environment, the methodologies used, and others) in which the study was conducted;

QQ 4: The study presents a clear justification for the methods used during its conduction;

QQ 5: There is a clear statement of contributions and data are presented to support them;

QQ 6: The authors explicitly discuss the credibility and limitations of their results;

QQ 7: The authors discuss the future work based on the contributions of the study.

Figure 2 shows the conduction process considering steps and products.

\subsection{Step 2: Conducting}

Primary studies were retrieved, selected, and evaluated according to the protocol. JabRef ${ }^{6}$, a free software for references management, was used to support the organization and analysis of primary studies. The selection of primary studies was divided into two steps: (i) Reading of the title and abstract, followed by a cross-validation of the results obtained by each reviewer, and when necessary, reading of the introduction and conclusion; and (ii) reading of the full study, and use of a form to perform data extraction. The evaluation of quality of included studies was performed and disagreements among researchers at any stage have been resolved in consensus meetings. The results of the search string applied in scientific basis are described in Table 3.2. Science Direct and Scopus were the basis with more returns, representing $21.45 \%$ and $34.76 \%$ of all returned studies, respectively. However, $A C M$ and Web of Science were more precise, returning a higher percentage of the included studies.

\subsection{Phase 3: Reporting}

Our search resulted in 466 primary studies for analysis. After removing 137 repeated studies, 327 were submitted to selection step. After reading titles, abstracts, and, when necessary, the introduction and conclusion of each study, the results obtained were subjected to a cross-validation, and 14

\footnotetext{
$\overline{{ }^{6} \text { http://jabref.sourceforge.net }}$
} 


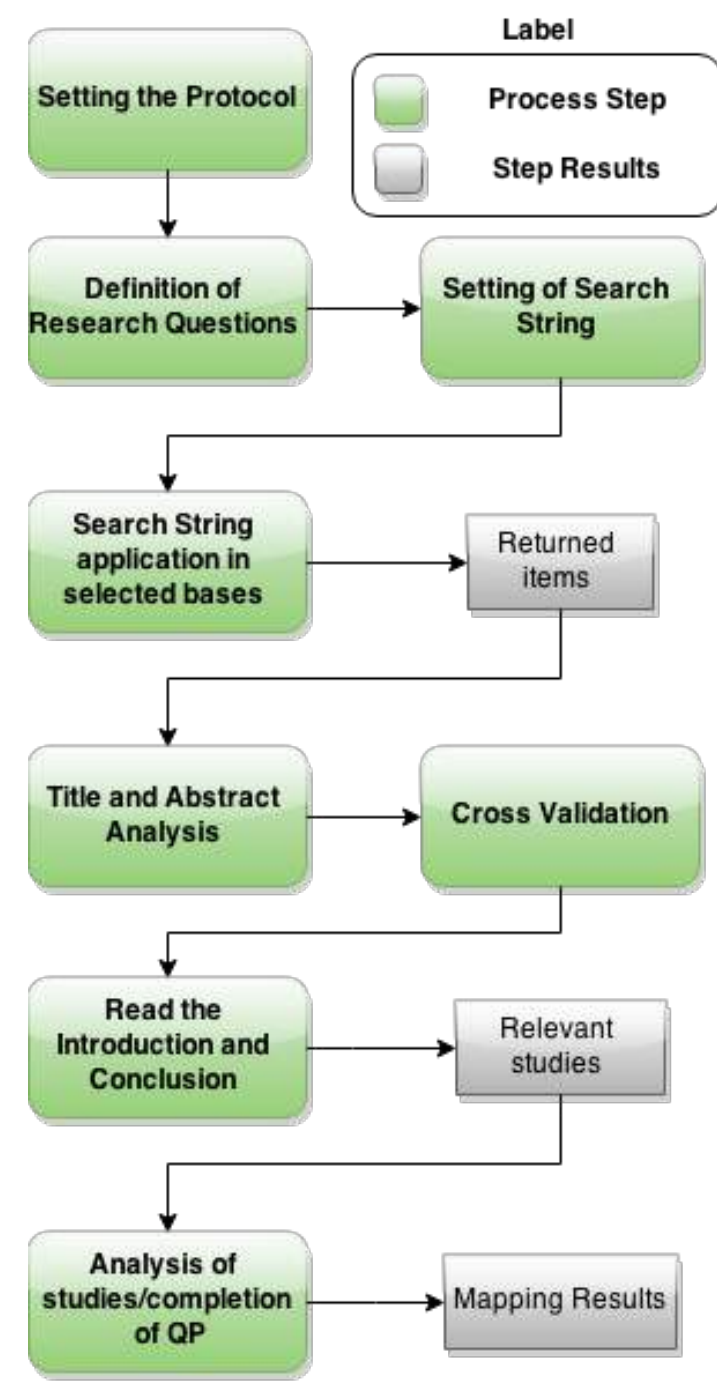

Figure 2: Systematic Mapping driving process of adapted Literature Tofan et al. [34].

primary studies were selected to be read in its entirety. Applying IC and EC, eight studies were chosen as included and reviewed. Table 3.3 presents the included studies and their respective years of publication. Table 3.3 shows selected studies. It brings original titles, as well as a brief summary of their contents.

RQ 1: Which methods, techniques, actions, processes and/or activities have been used to align $\mathrm{OC}$ and the use of AM?

Considering models to align OC and AM, only Kompella et al. (2014) [22] (from the eight included studies) explicitly present a set of recommended actions to align OC and AM. Their study presents an approach for changes that must be implemented in the organization. They consider people, processes, methodologies, and practices, and elaborate steps to follow in order to achieve results, and to benefit the emerging agility, aligning as result, the current $\mathrm{OC}$ and the $\mathrm{AM}$ adopted. They observed teams that use Scrum to reach their findings. Authors conclude that agility is influenced by the following list of factors related to OC: (i) strategies,

\begin{tabular}{lccc}
\hline Basis & Returned & \% Total & Selected \\
\hline ACM & 86 & $18,45 \%$ & 4 \\
IEEE & 48 & $10,30 \%$ & 1 \\
Science Direct & 100 & $21,45 \%$ & 0 \\
Scopus & 162 & $34,76 \%$ & 1 \\
Web of Science & 70 & $15,02 \%$ & 2 \\
\hline
\end{tabular}

Table 2: Statistics Used Primary Studies

\begin{tabular}{lll}
\hline ID & Study Included & Year \\
\hline S1 & Kerstin Siakas, Errikos Siakas [30] & 2007 \\
S2 & D. Strode, S. Huff, A.Tretiakov [33] & 2009 \\
S3 & Juhani Iivari, Netta Iivari [17] & 2010 \\
S4 & Tolfo et al. [35] & 2011 \\
S5 & Livari, Netta Livari [18] & 2011 \\
S6 & Stavros Stavru et al. [32] & 2012 \\
S7 & Juhani Dorairaj, Noble e G. Allan [10] & 2013 \\
S8 & Kompella et al. [22] & 2014 \\
\hline
\end{tabular}

Table 3: Primary Studies List Included

plans and company's major goals; (ii) proposal of actions to achieve the planned goals; (iii) the growth in value delivery through the delivery of products; and (iv) training of employees to fulfill their actions.

In turn, Kompella et al. [22] prepare a process divided into stages in order to align the company's OC with the emerging agility. Their proposition is a training process to teach employees how to meet project's goals. There is not a validation step, since the conclusions come from observation. Furthermore, the study intention was providing insights, with no commitment of being a mature study. Their findings "suggest" that changes need to be performed to achieve the desired alignment, and a first step in this direction must be training the team. Additionally, they claim that an additional difficulty is choosing parameters to measure effectiveness of such an approach. They used customer satisfaction and productivity as parameters. However, they consider this a limitation since such parameters may vary according to the context where the project was conducted.

On the onther hand, Tolfo et al. [35] based their research on Schein's model and try to represent OC of three real companies. They mention the term "agile culture" as an ideal culture to adopt AM. Then, they characterize this agile culture using Schein's model divided into levels. Finally, authors mention that the $\mathrm{OC}$ of the analyzed companies are not compatible with the characteristics of the so-called agile culture. They conclude that aligning OC and AM consists of identifying the cultural levels of the organization and align them with the ideal agile culture. However, authors do not propose actions, activities, or models to achieve alignment between OC and AM. They only offer a first step in this direction.

Thus, we can deduce that there is still a necessity to consolidate a set of recommendations, procedures, processes or actions that can effectively achieve alignment between a company's OC and AM, reaching characteristics of the ideal agile culture. Proposals are still scarce and there is a significant lack of evaluation and validation.

RQ 2: Which OC factors impact the success of the AM adoption?

Regarding $\mathrm{OC}$ factors that impact the adoption of $\mathrm{AM}$, 


\begin{tabular}{|c|c|c|}
\hline ID & Title & Summary \\
\hline S1 & $\begin{array}{l}\text { The Agile Professional Culture: A Source of Agile } \\
\text { Quality [30] }\end{array}$ & $\begin{array}{l}\text { Comparisons between Schein, Mumford and agile principles in } \\
\text { order to present another perspective to be considered for AM } \\
\text { adoption. }\end{array}$ \\
\hline S2 & $\begin{array}{l}\text { The Impact of Organizational Culture on Agile } \\
\text { Method Use [33] }\end{array}$ & $\begin{array}{l}\text { Case study of development projects that use some agile techni- } \\
\text { ques, crossing results with the evaluation of a current OC. A set } \\
\text { of OC factors to use AM are reported. }\end{array}$ \\
\hline S3 & $\begin{array}{l}\text { Agile Methods and Organizational Culture: Re- } \\
\text { flections About Cultural Levels [35] }\end{array}$ & $\begin{array}{l}\text { Three real companies are analyzed based on the Schein's model. } \\
\text { Cultures and subcultures, and their influence on the adoption of } \\
\text { AM are investigated. }\end{array}$ \\
\hline S4 & $\begin{array}{l}\text { The Relationship Between Organizational Culture } \\
\text { and the Deployment of Agile Methods [18] }\end{array}$ & A literature review on OC with AM. \\
\hline S5 & $\begin{array}{l}\text { Organizational Culture and the Deployment of } \\
\text { Agile Methods: The Competing Values Model } \\
\text { View [17] }\end{array}$ & $\begin{array}{l}\text { Presents theories and models discussed in other studies. addres- } \\
\text { sing Competing Values Framework, and the Theoretical Model. }\end{array}$ \\
\hline S6 & $\begin{array}{l}\text { Organizational Values and Agile Methods Deploy- } \\
\text { ment [32] }\end{array}$ & $\begin{array}{l}\text { Proposes the creation of a model of OC that relates to AM from } \\
\text { other models such as Schein. }\end{array}$ \\
\hline S7 & $\begin{array}{l}\text { Agile Software Development with Distributed Te- } \\
\text { ams: Senior Management Support [10] }\end{array}$ & $\begin{array}{l}\text { Case study that investigates into the relationship between OC } \\
\text { and AM, the challenge of managing a multinational multiple } \\
\text { teams spread around the world working on the same project. }\end{array}$ \\
\hline S8 & $\begin{array}{l}\text { Agile Methods, Organizational Culture and Agi- } \\
\text { lity: Some Insights [22] }\end{array}$ & $\begin{array}{l}\text { An analysis of a company that adopts Scrum. The importance } \\
\text { of teamwork is highlighted, focusing on communication, culmi- } \\
\text { nating in a process. }\end{array}$ \\
\hline
\end{tabular}

Table 4: Title and brief summary of each included study.

Strode et al. [33] identify such factors. From a list of nine factors, they survey the most common practices of AM, identifying six factors that contributes to link OC with the adoption of AM: (i) The organization fosters feedback and learning; (ii) Social interactions within the organization are reliable and collaborative, (iii) The project manager plays a facilitator role, (iv) The management style is of leadership and collaboration, (v) Teamwork in organization is flexible and participatory and encourages social interaction, (vi) the organization encourages training.

Siaskas and Siaskas [30] investigate the relationship between the types of culture proposed by Hofstede [15] (in a taxonomy which includes Democratic, Clan, Hierarchical and Disciplined), checking that one in which "agile culture" would fit more easily. According to them, AM should be considered a subculture within the existing OC, and under this perspective, the type of culture called democratic is characterized as the most appropriate, since it enhances factors such as flexibility and spontaneity within the organization's hierarchy. Following this line of reasoning, we can conclude that one of the important factors that positively impact the adoption of AM is the type of culture existent. Those factors are similar to those found by Strode et al. [33].

Livari et al. [18] also identified specific types of culture that foster adoption of AM. They present hypothesis about a specific type of OC called "developmental" [25], that is more flexible and focused on adapting the organization to change. Finally, Livari and Livari [17] present results that summarize the main advances of some authors on the subject. Researchers claim that the relationship between $\mathrm{OC}$ and the use of AM need to be performed under the perspective of a specific model of OC (Competing Values Model). It has been initially proposed by Quinn and Rohrbaugh [25] to identify key indicators of effective business, and raise a number of hypothesis showing some barriers to the adoption of AM. Table 5 summarizes one of the remarkable taxono- mies of $\mathrm{OC}$ and how they impact adoption of AM (positively or negatively). Data were collected from included studies. According to the table, cultures are classified as developmental, group, hierarchical, and rational. When analyzing if the adoption of AM is positively of negatively influenced by them, only hierarchical (one with a rigid hierarchy, and low levels of communication and flexibility) impacts negatively on AM adoption. Thus, the type of culture is also an important factor that influences and impacts the success of the AM adoption.

\begin{tabular}{|l|c|c|}
\hline $\begin{array}{l}\text { Culture Type vs Influence } \\
\text { on AM }\end{array}$ & Positive & Negative \\
\hline Developmental & $\mathrm{X}$ & \\
\hline Group & $\mathrm{X}$ & \\
\hline Hierarchical & $\mathrm{X}$ & $\mathrm{X}$ \\
\hline rational & $\mathrm{X}$ & \\
\hline
\end{tabular}

Table 5: Types of Culture and the types of influence in AM proposed by Livari and Livari [18]

Table 6 compiles a set of factors that influence the OC in the adoption of AM, according to the studies analyzed. It was observed that, if the factors listed are present in the current OC, they receive and facilitate the adoption of AM, impacting positively. Similarly, if they do not exist in the current culture, this impacts negatively on the adoption of AM.

RQ 3: Organizations implementing AM have awareness about the influence of $\mathrm{OC}$ in their projects?

Two out of eight studies (S6 and S7) considered the assessed organizations unaware of the influence of OC in AM adoption. Remaining six studies, in turn, do not even mention if there is any awareness of the influence of OC on AM in the analyzed companies. In studies such as Tolfo et al. [35], in particular, authors report a large gap between what is 


\begin{tabular}{|l|l|}
\hline Studies & Organizational Culture Factors \\
\hline S1, S5 & Division of roles \\
\hline S1, S3, S4 & Management values innovation \\
\hline $\begin{array}{l}\text { S1, S2, S7, } \\
\text { S8 }\end{array}$ & Leadership encourages feedback \\
\hline S2,S3 S4 & Leadership takes risks \\
\hline S2, S3 & Organization values collaboration \\
\hline S1, S2, S4 & Organization allows flexibility of teams \\
\hline S4, S8 & $\begin{array}{l}\text { Organization does not have a centralized } \\
\text { hierarchy }\end{array}$ \\
\hline S1 & Satisfaction \\
\hline S3, S8 & Decision making is shared \\
\hline S2, S3, S8 & Teamwork is valued \\
\hline
\end{tabular}

Table 6: Factors that influence OC in adopting AM.

thought to be an agile culture and the practices really disseminated in the company. They analyze real organizations that follow agile values, and that references agile practices in its mission. They conclude that, when looking at deeper levels (second and third) of their OC, there is a misalignment with these values, and therefore an unawareness of the influence of such levels in the application of methodologies. Therefore, there is an indication that the alignment of the OC for AM adoption is still a little known practice. People are not awareness about the OC impact on AM adoption and in the companies routine as a whole.

RQ 4: Which difficulties are reported by studies investigating $\mathrm{OC}$ in the context of $\mathrm{AM}$ ?

Volatility of term "agility" is one of the important difficulties reported by the studies. Two of them (S3 and S4) address more deeply what can be considered "agility". Seven cite the Agile Manifesto's conception of agility [1] as the main guide (only S6 does not mention Agile Manifesto). Three (S4, S5, and S8) deal with agility as an emergent property. From this perspective, agility arises from the interplay between the adopted methodology and working practices and culture already internalized in the organization. Thus, agility is a dynamic property that may emerge or not. In this direction, it is necessary to define a set of parameters that can be used to classify and evidence the emergence of "agility", a difficulty reported by the studies. There is no consensus in defining what it is, and there is a tendency to consider as agile any flexible or adaptable development process.

In addition to the volatility of the term "agility", other difficulties related to $\mathrm{OC}$ in projects that adopt AM are reported by studies such as (i) OC factors related to AM can not be generalized, since there are variables such as organizational environment and national culture that influence in each context; (ii) there is a complex and dynamic relationship between the $\mathrm{OC}$ and $\mathrm{AM}$ that poses additional challenges to organizations since continuous monitoring is necessary, identifying the influences from both parts of the $\mathrm{OC}$ in the $\mathrm{AM}$, and $\mathrm{AM}$ in $\mathrm{OC}$; (iii) studies using very strict techniques of scientific research (such as surveys for analysis of OC) may have a "gap" in its results, only identifying the first level of $\mathrm{OC}$, which is usually contrasting with the deeper OC levels (second and third).

\subsection{Threats to Validity}

Table 7 brings the quality evaluation results of the studies according to the criteria described in the protocol. Based on the results it is noteworthy that all the studies met the QQ1 and QQ2, and four (S1, S2, S4, and S8) of the studies did not meet the QQ7, i.e. they did not presented perspectives for future work, which does not impact reliability of the data collected. QQ6 identifies that there were studies that do not explicitly showed the limitations of their results. However, these data do not affect the reliability of the results.

\begin{tabular}{cccc}
\hline Quality Issues & Yes & Some extent & No \\
\hline QQ1 & 8 & 0 & 0 \\
QQ2 & 8 & 0 & 0 \\
QQ3 & 6 & 2 & 0 \\
QQ4 & 7 & 1 & 0 \\
QQ5 & 4 & 3 & 1 \\
QQ6 & 4 & 3 & 1 \\
QQ7 & 3 & 1 & 4 \\
\hline
\end{tabular}

Table 7: Answers to Quality Questions.

We have also concerned with the validity of results of our systematic mapping. The following main threats to validity identified for this SMS were considered [24]:

- Missing of important primary studies: The publication databases used in this systematic study are considered the most relevant ones [12]. In addition, no limit was placed on the date of publications. However, some primary studies may have been missed;

- Reviewers reliability: None of the included studies were developed by research groups related to us. Therefore, we are not aware of any bias we may have introduced during the analysis. However, conclusions might have been influenced by reviewers' opinions; and

- Data extraction: Since not all information was obvious to answer the research questions, some data had to be interpreted. Thus, to ensure the validity of this systematic mapping, discussions were conducted whenever a disagreement between the reviewers occurred.

\section{DISCUSSION}

Included studies present a variety of publication vehicles. Four were published in conferences (S2, S6, S7, S8), highlighting the International Workshop on Cooperative and $\mathrm{Hu}-$ man Aspects in Software Engineering (CHASE), currently the most important discussion forum for $\mathrm{OC}$ in context of AM. One is a book chapter (S3), and the remaining three were published in journals (S1, S4, S5). In turn, publications origins are diverse as Brazil, Bulgaria, Canada, Greece, India, and New Zealand, each country contributing with only one study. Finland, distinctly, is represented by two studies.

Regarding the models to align OC and AM, only the study of Kompella [22] presented an explicit model, while Tolfo et al. [35] presented an indication of what could be a first step in this alignment. However, this model has not been validated effectively, and was applied only in the context of a specific AM (Scrum). Studies have established relations between these topics, without offering explicit actions for alignment and resolution of possible conflicts between the OC and AM adopted by organizations. Therefore, it is necessary to propose or adapt models, actions, and strategies that extend the results achieved, promoting more comprehensive approaches 
that could be adopted by other AM, such as XP, Crystal, and Feature-Driven Development (FDD).

Considering OC factors that influences AM, despite the absence of specific actions, all evaluated studies raise at least one $\mathrm{OC}$ factor that has been confirmed to influence the adoption of AM, and this fact shows that factors such as lack of teamwork spirit, flexibility to change, and feedback are considered in most studies. Type of culture (considering those presented in OC taxonomies), and characteristics of the current culture are also important factors that impacts AM success.

Regarding the awareness of companies analyzed in studies on the influence of $\mathrm{OC}$ and AM, only two studies reported this kind of concern. Other studies are silent on this point. Therefore it can be assumed that there is need to disseminate awareness of $\mathrm{OC}$ and its importance in organizations. Additionally, the disparity between the intention to be agile and the reality in the company (the current OC) is highlighted.

Finally, the analysis of selected studies shows that there is still a lack of consensus on agility concept, especially taking into consideration emerging agility vision, what is considered a difficulty associated to the alignment of OC and AM. A massive reference to the Agile Manifesto [1] as a source of enlightenment to define AM was identified. Under this perspective, agility is an inseparable result of $\mathrm{AM}$, a fallacious conclusion. By analyzing companies, studies conclude that adoption of AM does not guarantee that the organization reaches the desired agility. In most of the analyzed studies, the adoption of AM is given by the desire of the organizations to deal with frequently changing requirements, which often leads to short deadlines for decision-making and low quality results. The team that uses it must have characteristics that give support to the deployed process. Following this line of reasoning, Siaskas and Siaskas [30] identify that, considering the model of four types of OC proposed by Hofstede [15], the OC called democratic owns most of the characteristics aligned to the use of AM. As a corollary, the type of culture is an impacting factor on the success of AM adoption. Some of them have been considered more welcoming to AM approach, specially those with a high level of flexibility, intensive communication, team spirit, collaboration, and leadership management.

From the results we externalized the following research perspectives:

Concise definition of an ideal Agile Culture: IS development companies need to be investigated considering distinct types of AM, in order to characterize a concise, unified, and genuine conception of an ideal agile culture for AM adoption;

A unifying taxonomy for OC: Different names, OC types, and taxonomies are presented by the studies. An effort should be performed to unify those notations, creating a broad, complete, and coherent taxonomy for OC;

OC Alignment Models for AM: an investigation can be conducted to propose a set of models, practices, processes, techniques, and tools to support the alignment of OC with AM. Additionally, it is necessary to characterize the current OC in the organization and bring it closer to a culture that promotes agile values. In this sense, templates, checklists, and other procedures can be investigated to support this systematic alignment;

OC factors influencing AM: more studies are needed to validate the results already found. It is necessary to investigate other factors that influence the $\mathrm{OC}$ in $\mathrm{AM}$, as the National Culture. A mapping of specific factors of OC (as the influence of work space organization) that directly or indirectly influence in adopting $\mathrm{AM}$ is required, diagnosing the weight of each of the factors elicited in adopting AM, and how those factors influence the different types of AM adopted in companies such as Scrum, FDD, and TDD;

Awareness of OC in companies that adopt AM: studies can be conducted to investigate how companies applying AM have had access to OC concept, and the impact of this awareness in the company's daily routine. In this sense, research on the consciousness of the OC in AM can be conducted to understand the influence of OC. This can be used as an input to derive a set of decisions to modify the work environment. Those actions can support the achievement of characteristics to foster the adopted AM;

OC negative factors impacting on the adoption of AM: some characteristics of a current OC can be negative, such as inappropriate behavior, insubordination, immaturity of the teams, "culture of blame" [35], among others. A meticulous analysis can be performed to elicit factors that negatively influence the OC, directly impacting the success of AM adoption. The identification of these points can enable the adoption of contingency actions, motivating changes in the current $\mathrm{OC}$.

\section{FINAL CONSIDERATIONS}

This paper presented results of a Systematic Mapping Study (SMS) which was carried out to investigate the influence of organizational culture (OC) in the context of IS software development companies which works with Agile methodologies (AM). Studies that investigate the relation between $\mathrm{OC}$ and AM were analyzed. As main contributions of this study, we can highlight the (i) compilation of a list of OC factors that are relevant and that effectively influence the success of AM; (ii) an overview of the OC area in the context of IS companies and studies dealing with AM; and (iii) research perspectives reporting unexplored gaps and research opportunities. These research directions involve the development of new models of action and/or practical methods, strategies, processes, guidelines, protocols, and other artifacts to assist IS software development companies to deploy $\mathrm{AM}$ without major difficulties, aligning the current OC to suitably fit agile practices. Such data and conclusions can support decision-making within a project or company. This study can contribute to those interested in this topic, serving as an starting point for future research and advances, in particular for the proposal of a model of actions to support a systematic proposal to align $\mathrm{OC}$ and AM. Additionally, this study contributes to the advancement of the state-of-art in research of a sociotechnical approach to enable IS software development in the Brazilian community, addressing a recurrent social aspect (OC), rising and correlating it with a disseminated technical practice of software development $(\mathrm{AM})$.

\section{REFERENCES}

[1] Agile manifesto. www.agilemanifesto.org, 2001. Acessado em 10 de janeiro de 2015.

[2] Adoption of agile methods. http://www.methodsandtools.com/dynpoll/ 
oldpoll.php?Agile2, 2008. Acessado em 5 de fevereiro de 2015.

[3] M. S. Ali, M. A. Babar, L. Chen, and K.-J. Stol. A systematic review of comparative evidence of aspect-oriented programming. IST, 52(9):871-887, 2010.

[4] Aoyama. M. agile software process and its experience. In ICSE, 1998.

[5] K. Cameron and R.E. Diagnosing and chaging organizational culture: Based on the competing values framework. Reading MA: Addison-Wesley, 1999.

[6] T. Chow and L. Cao. A survey of critical sucess factors in agile software projects. JSS, 2008.

[7] A. Cockburn. Agile software development. Boston, Addison-Wesley., 2002.

[8] G. Correia, J. P. Amaral, V. V. Graciano Neto, and P. G. F. Matsubara. Influence of organizational culture in the adoption of agile methods : Preliminary results of a systematic review (in portuguese). In Proceedings of the 1st National Information Management Meeting, ENGI '14, pages 1-6, Goiânia, Brazil, 2014. UFG.

[9] E. G. da Costa Filho, R. Penteado, J. C. A. Silva, and R. T. V. Braga. Padrões e métodos ágeis: agilidade no processo de desenvolvimento de software. In Proc. of 5th Sugarloaf Plop, pages 156-169, 2005.

[10] S. Dorairaj, J. Noble, and G. Allan. Agile software development with distributed teams: Senior management support. ICGSE, pages 197-205, 2013.

[11] T. Dyba, B. Kitchenham, and M. Jorgensen. Evidence-based software engineering for practitioners. Software, IEEE, 22(1):58-65, Jan 2005.

[12] T. Dybaa and T. Dingsoyr. Empirical studies of agile software development: A systematic review. IST, 50(9):833-859, 2008.

[13] V. V. Graciano Neto, M. Guessi, L. B. R. Oliveira, F. Oquendo, and E. Y. Nakagawa. Investigating the model-driven development for systems-of-systems. In Proceedings of the 2014 European Conference on Software Architecture Workshops, ECSAW '14, pages 22:1-22:8, Vienna, Austria, 2014. ACM.

[14] J. HighSmith. Agile software development ecosystems. England: Addison-Wesley, 2002.

[15] G. Hofstede. Culture and organizations. International Studies of Management $\&$ Organization, pages 15-41, 1980.

[16] C. I. Administração nos Novos Tempos: Os novos horizontes da administração. Campus: Rio de Janeiro, 1999.

[17] J. Iivari and N. Iivari. Organizational culture and the deployment of agile methods: The competing values model view. Springer Berlin Heidelberg, 2010. cited By (since 1996)1.

[18] J. Iivari and N. Iivari. The relationship between organizational culture and the deployment of agile methods. IST, 53(5):509-520, May 2011.

[19] S. M. M. M. K. Petersen, R. Feldt. Systematic mapping studies in software engineering. ICEAS, 2008.

[20] B. Kitchenham, O. P. Brereton, D. Budgen, M. Turner, J. Bailey, and S. Linkman. Systematic literature reviews in software engineering-a systematic literature review. IST, 51(1):7-15, 2009.
[21] B. Kitchenham, R. Pretorius, D. Budgen, O. P. Brereton, M. Turner, M. Niazi, and S. Linkman. Systematic literature reviews in software engineering-a tertiary study. IST, 52(8):792-805, 2010.

[22] L. Kompella. Agile methods, organizational culture and agility: Some insights. In Proceedings of the 7th International Workshop on Cooperative and Human Aspects of Software Engineering, CHASE 2014, pages 40-47, New York, NY, USA, 2014. ACM.

[23] R. H. L. . S. M. M. H. Mohammad Jasim Uddin. Impact of organizational culture on employee performance and productivity: A case study of telecommunication sector in bangladesh. International Journal of Business and Management, 2013.

[24] L. B. R. Oliveira, F. S. Osório, and E. Y. Nakagawa. An investigation into the development of service-oriented robotic systems. In Proceedings of the 28th Annual ACM Symposium on Applied Computing, SAC '13, pages 223-228, Coimbra, Portugal, 2013. ACM.

[25] R. E. Quinn and J. Rohrbaugh. A spatial model of effectiveness criteria: Towards a competing values approach to organizational analysis. Management science, 29(3):363-377, 1983.

[26] S. S. S. Sarker. Exploring agility in distributed information systems development teams: an interpretive study in an offshoring context. ISR, 2009.

[27] E. H. Schein. Organizational culture and leadership. Jossey-Bass Inc, 1985.

[28] E. H. Schein. Organizational culture and leadership, volume 2. John Wiley \& Sons, 2010.

[29] K. Schwaber and M. Beedle. Agile software development with Scrum. New Jersey: Prentice Hall, 2002.

[30] K. V. Siakas and E. Siakas. The agile professional culture: A source of agile quality. Softw. Process, 12(6):597-610, Nov. 2007.

[31] D. Šmite, C. Wohlin, T. Gorschek, and R. Feldt. Empirical evidence in global software engineering: a systematic review. Empirical software engineering, 15(1):91-118, 2010.

[32] S. Stavru. Organizational values and agile methods deployment. In V. Cortellessa, H. Muccini, and O. Demirors, editors, 38th ECSEAA, pages 282-285. IEEE Computer Soc, Los Alamitos, 2012.

[33] D. Strode, S. Huff, and A. Tretiakov. The impact of organizational culture on agile method use. In 42nd HICSS'09, pages 1-9, Jan. 2009.

[34] D. Tofan, M. Galster, P. Avgeriou, and W. Schuitema. Past and future of software architectural decisions - a systematic mapping study. IST, 56(8):850 - 872, 2014.

[35] C. Tolfo, R. S. Wazlawick, M. G. G. Ferreira, and F. A. Forcellini. Agile methods and organizational culture: Reflections about cultural levels. J. Softw. Maint. Evol., 23(6):423-441, Oct. 2011. 